\title{
Vestibular frenectomy in periodontal plastic surgery
}

\author{
V. Monnet-Corti 1,2 , A. Antezack ${ }^{1,3}$, V. Moll1,4 \\ 1 Public assistance - Hôpitaux de Marseille (Hôpital de la Timone-AP-HM, Pôle Odontologie)-UFR \\ Odontology, Aix- Marseille Université \\ 2 Professor of Universities. Hospital practitioner. President of the French Society of Periodontology \\ and Oral Implantology \\ 3 Oral Medicine Resident \\ ${ }^{4}$ Assistant Hospital-University Periodontology-Private Practice in Martigues
}

\begin{abstract}
Vestibular frena are bands of soft tissue that connect the lip or cheek to the alveolar mucosa or to the gum and that can restrict their movements. These mucosal folds can, in some cases, attach too close to the teeth and are associated to a persistent diastema. Additionally, if this frenum is too tight, it can cause gum recession by pulling the gums away from the teeth. The position of a frenum can become more apical and be corrected during growth with anterior teeth eruption. However, when it causes self-consciousness, pain, or gum recession, a frenectomy is indicated. The frenectomy is a simple procedure which involves total surgical removal of a frenum. The presence of a hypertrophic maxillary vestibular medial frenum associated with a diastema is the most commonly encountered indication in children. Its elimination will contribute to diastema closure that will stay stable over time.
\end{abstract}

\section{KEYWORDS}

Median maxillary labial frenum, median mandibular labial frenum, diastema, frenectomy, periodontal plastic surgery

\section{INTRODUCTION}

In the oral cavity, mucosal folds stretching between the alveolar mucosa and the keratinized and attached gingiva are intended to stop, control, or limit the movements of anatomical regions. These folds are referred to as frena (singular "frenum"). They include the median labial, vestibular, maxillary, and mandibular frena, which limit lip movements; the labial and medial lingual frena, which limit tongue movements; and the lateral vestibular frenum, which limits cheek movement?

Median vestibular, maxillary, and mandibular frena were described by Placek et al.

\section{Address for correspondence:}

Virginie Monnet-Corti - 27 Boulevard Jean Moulin - 13385 Marseille

E-mail: virginie.monnet@ap-hm.fr

Article received: 26-10-2017. Accepted for publication: 28-11-2017.

This is an Open Access article distributed under the terms of the Creative Commons Attribution License (http://creativecommons.org/licenses/by/4.0), which permits unrestricted use, distribution, and reproduction in any medium, provided the original work is properly cited. 
$(1974)^{32}$ in terms of their attachments relative to marginal periodontium. They proposed the following classification: see Fig. 1a, b, c, and d.

This classification can also be used to distinguish between the attachment of the lateral and the lingual frena. In 2011, a study with 226 children (mean age 8.5 years), in terms of maxillary median maxillary frenum attachment, $10.2 \%$ children had mucosal attachment, $41.6 \%$ had gingival attachment, $22.1 \%$ had papillary

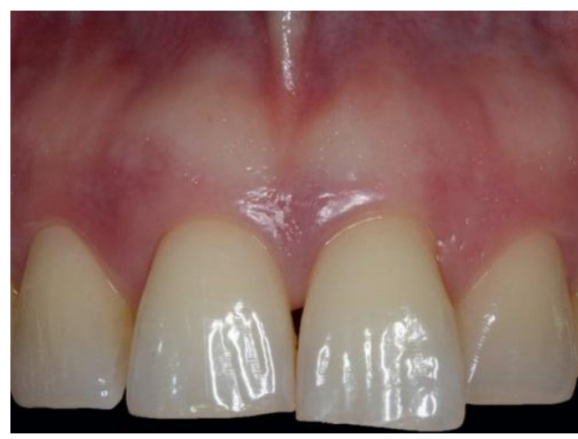

Figure 1a

Mucosal attachment: maxillary labial frenum is attached to the alveolar mucosa at the edge of the mucogingival line.

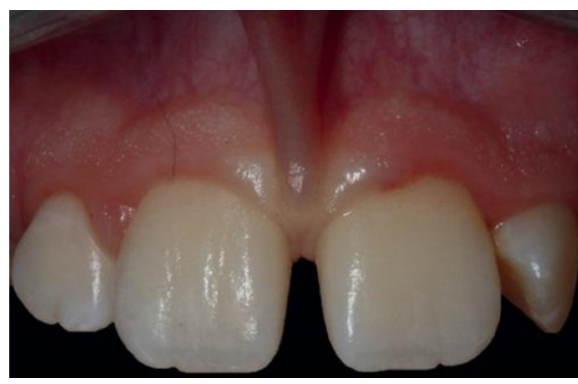

Figure $1 c$

Papillary attachment: the maxillary labial frenum is attached to the papillary gingiva.

The mobilization of the lip (tensile test) results in this case a displacement of the marginal gingival of the central incisors. attachment, and $26.1 \%$ had interdental attachment ${ }^{8}$. In other words, 48.2\% frena had attachment interfering with the sulcus. A gingival-mucosal frenum has a single attachment distributed over two or three attachment points ${ }^{18}$, and this is most commonly seen with the lateral frenum. A frenum is not responsible for periodontal pathology or the presence of a diastema. It can be considered as an associated unfavorable anatomical factor. They may represent

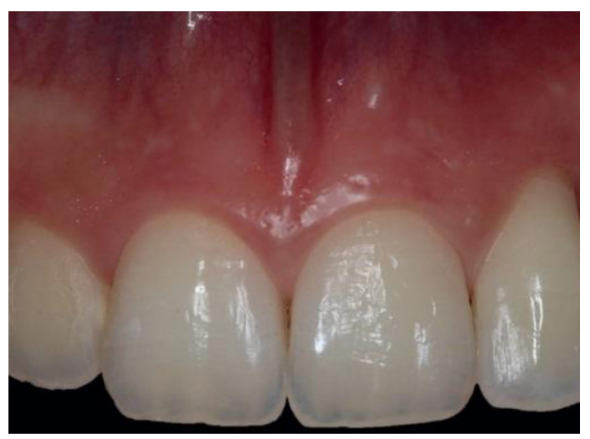

Figure $1 b$

Gingival attachment: Low attachments of maxillary labial frena are embedded in the attached gingiva.

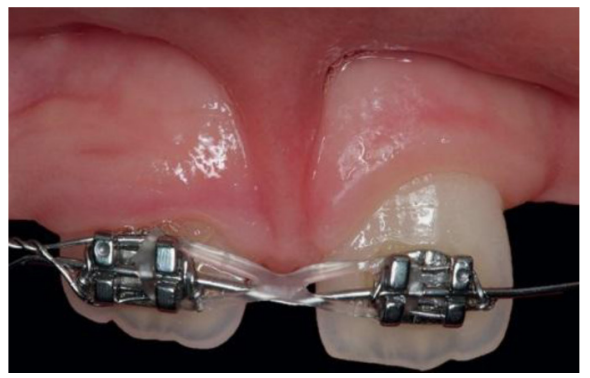

Figure 1d

Interdental attachment: maxillary labial frenum joins the top of the gingival septum and merges with the bunoid papilla. This anatomical situation is generally related to the persistence of the interincisal diastema. 
an anatomical anomaly of the gingiva and/or the alveolar mucosa ${ }^{31}$.

For this reason, complete or partial removal of frena may be indicated for periodontal and/or orthodontic reasons.

The frenectomy must be part of the treatment plan for other defects or pathologies ${ }^{29}$. These include

- limitation of tongue and lip movements;
- orthodontic closure of a diastema;

- purely esthetic indications;

- gingival or periodontal recessions;

- position on edentulous ridge that impedes the completion of a prosthesis;

- associated lack keratinization;

- mobile mucosa around implants;

- periodontal disease linked to the presence of plaque and preventing the maintenance of hygiene.

\section{INDICATIONS FOR VESTIBULAR FRENECTOMY}

Frenectomy may be performed for periodontal and orthodontic indications.

\section{Periodontal Indications}

Frenum exerting marginal gingiva traction and/or obstructing hygiene.

A "normal" frenum is attached a few millimeters from the marginal gingiva, delimiting a band of keratinized tissue and attached coronally to the frenum attachment. ${ }^{17}$

A very large frenum can also simply prevent periodontal or even oral hygiene (Fig. 2) because of its volume.

When this mucosal fold moves during the muscular movements for phonation, facial expressions, and chewing, the tissues to which it is attached are pulled.

If these tissues that frena are attached to are keratinized and attached to the gingiva, tissue movement will be absent. If, on the other hand, frena are attached to the free gingiva or if a periodontal lesion or recession has caused the tissues to migrate till the attachment, there will no longer be any keratinized tissue or attached gingiva ${ }^{38}$, resulting in the opening of a gingival sulcus or a periodontal pocket (Fig. 3).

If only the alveolar mucosa remains, maintaining good oral hygiene becomes difficult because it is painful, and gingival inflammation is likely to promote the progression of gingival recession (especially in children) ${ }^{35}$, or the formation of periodontal pockets.

Ramfjord $^{36}$ (1993) based the indication of frenectomy primarily on the possibility to maintain gingival health through proper hygiene. In these circumstances, frena are considered

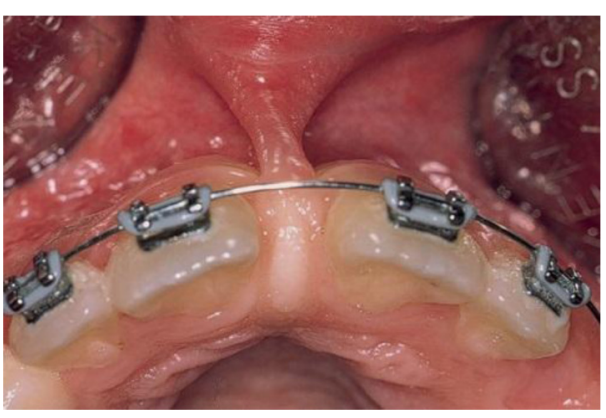

Figure 2

Frenum attachment in the palatal papilla. 


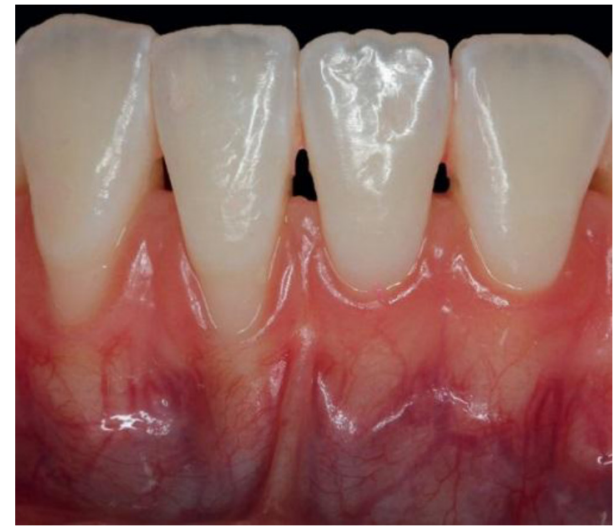

Figure 3

Apical traction of the tissues bordering the recession on 41 by the medial vestibular mandibular frenum.

minor etiological factors in periodontal pathology and/or more effective etiological factors in mucogingival problems. ${ }^{5}$

Lateral frena frequently exert traction on the free gingiva and make the vestibule shallow, impeding the passage of the toothbrush.

The traction exerted by the frenum on the marginal periodontium is harmful because it can:

- open the gingivodental sulcus;

- allow the accumulation of bacterial plaque ${ }^{21}$;

- interfere with hygiene (especially if there is no keratinized gingiva at all) ${ }^{4}$;

- apical traction on the tissues at the bordering an early recession;

- tension on surgically displaced tissues.

This unfavorable clinical situation frequently encountered with Placek ${ }^{32}$ type3 and type-4 frena. Without intervention, the orofacial muscles of facial expression and the movement of the lips and cheeks can move the free gingiva.
In the presence of type-IV periodontium in Maynard and Wilson (1980) ${ }^{23}$ classification, the situation represents an area of weakness.

The following associated clinical signs indicate a frenectomy: ${ }^{27}$

- Whitening of the internal papilla or the free gingiva during traction; ${ }^{11}$

- The limitation of labial or lingual movement (short and taut frenum);

- The proximity of attachment to the free marginal gingiva;

- The large width of the frenum at its attachment ${ }^{13}$;

- The opening of the gingivodental sulcus during traction.

\section{Unesthetic frena}

Elimination of unsightly frena has its place in the overall therapeutic arrangement of Class-1 and Class-2 malocclusions $^{22}$ and the treatment of gingival contour asymmetries (line of necks) ${ }^{25}$ (Fig. 4a and b).

In most cases, a simple movement of the frenum attachment is sufficient.

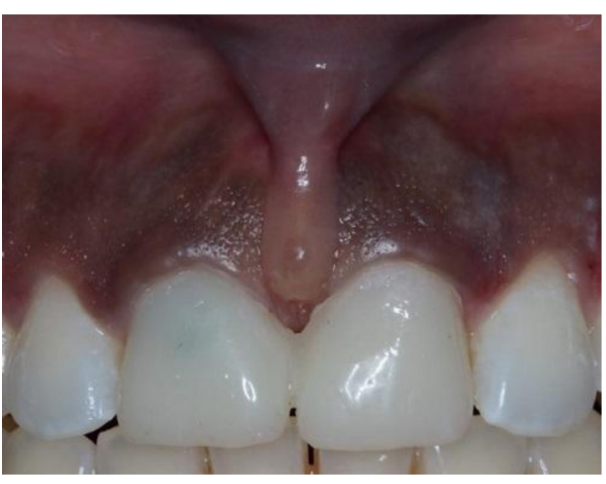

Figure 4a

Hypertrophic median upper labial associated with incomplete passive eruption of 11,12 , and 21. 


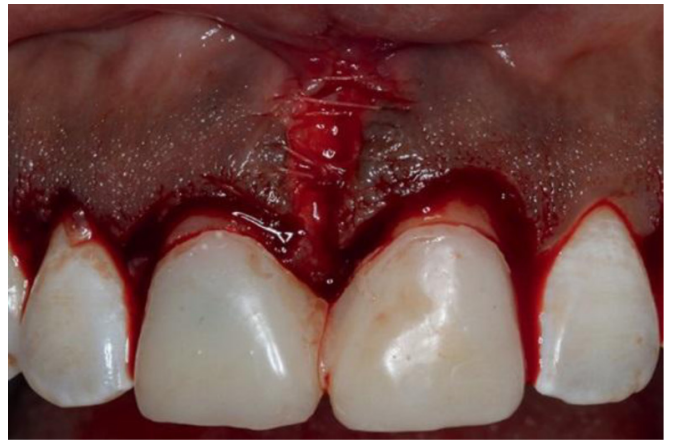

Figure $4 b$

Frenectomy associated with surgical coronal elongation to harmonize the gingival contour.

It must not leave a scar. Frenectomy will be esthtetically satisfactory more frequently when associated with a laterally positioned flap technique ${ }^{24}$ or a gingival ${ }^{5}$ graft to cover the excised site.

\section{Frenum-related with periodontal pathology}

During development of periodontitis and the evolution of a periodontal pocket, a frenum can become harmful by exerting traction on delicate tissues in the region of the pocket in question. However, it may not interfere when the periodontium is healthy. The mandibular frenum is associated with recessions in 5\% patients studied by Bork and Weiler $(1958)^{6}$, regardless of age.

The presence of a bulky frenum or frenum attached in the keratinized tissue may compromise the stability of postoperative periodontal tissue; periodontal treatment must involve tissue movement and impeccable postoperative immobility to treat the deep periodontium (guided tissue regeneration, induced tissue regeneration, bone filling, coronally positioned flap) or marginal periodontium (displaced flaps associated or not associated with connective tissue grafts, tunneling).

The frenum may simply be shifted apically, at least 15 days before the operation. In some cases, frenectomy is performed during surgical treatment (Fig. 5a, b, c, and d).

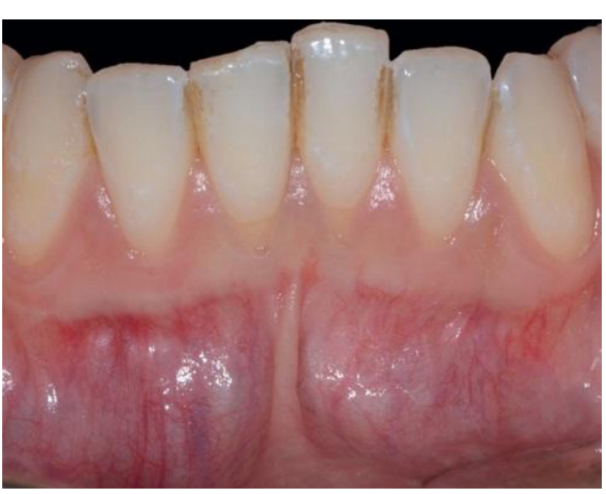

Figure 5a

Photograph at initial presentation: presence of gingival recessions on 31, 32, 41, and 42 associated with a traction of the lower labial frenum.

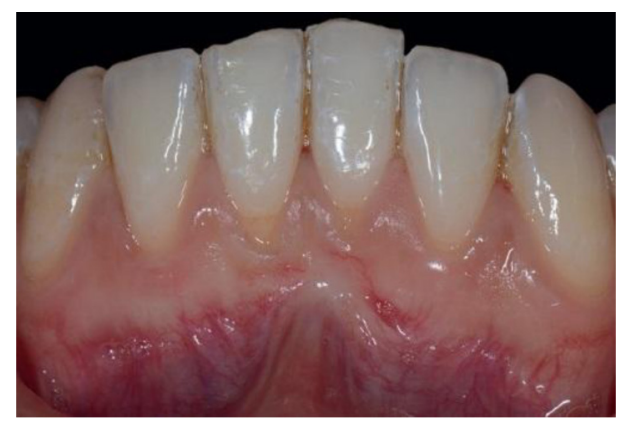

Figure $5 b$

Photograph after frenectomy. 


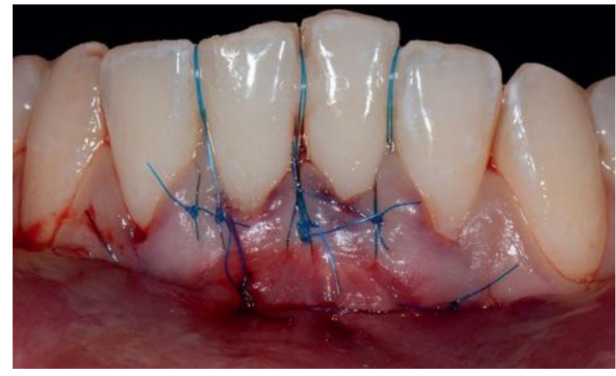

Figure 5c

Immediate postoperative photograph after buried connective graft transplant.

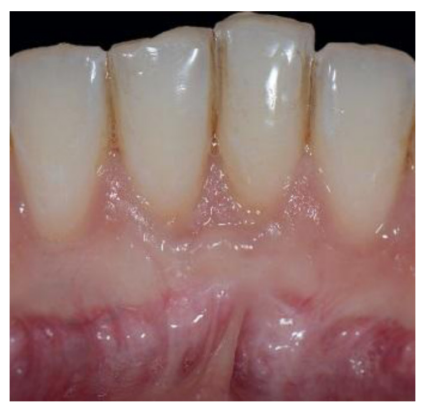

Figure $5 b$

Situation at 6 months postoperatively.

\section{Orthodontic Indications}

\section{Hypertrophic median frenum and anterior superior diastema}

A hypertrophic median frenum may interfere with the orthodontic closure of certain diastemas (Fig. 6a and b).

Even if the indications for frenectomy along with diastema closure are not common, it remains optional ${ }^{33}$. In many cases, interincisal diastemas close spontaneously $12,13,37$.

The spontaneous closure of diastemas depends on the action of three processes:

- centripetal pressure exerted by the eruption of surrounding teeth, and in particular maxillary canines;

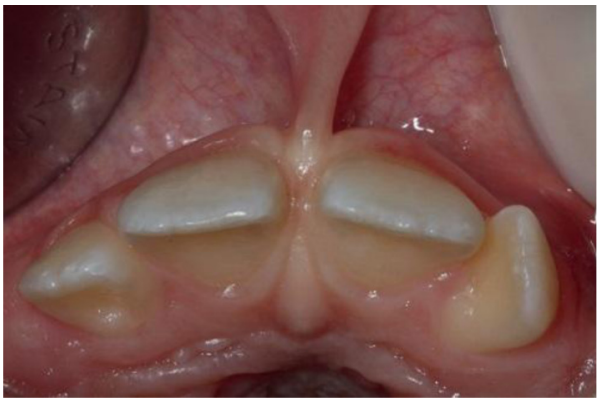

Figure 6a

Occlusal view of a hypertrophic frenum associated with the presence of an interincisal diastema.

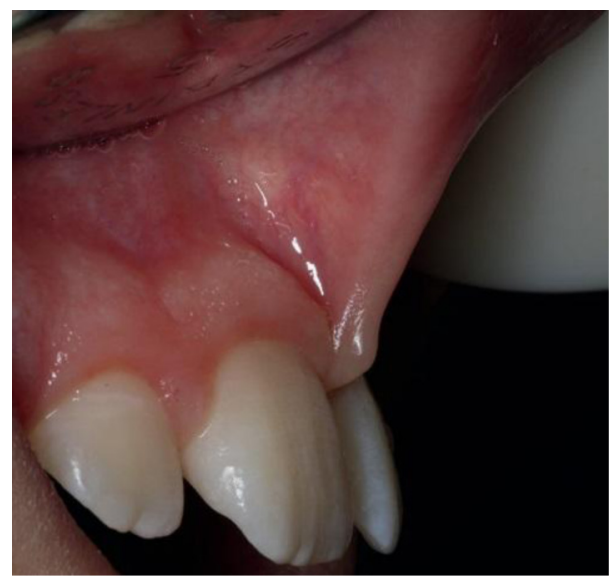

Figure $6 b$

Lateral view.

- growth of the premaxilla;

- contractile force of trans-septal interincisal fibers.

Thus, the presence of agenesis, an eruption, growth anomaly, and/or an interruption of the contractile fibers causes the diastema to persist. However, the indications for frenectomy associated with an orthodontic diastema closure is based on studies by Ewen and Pasternak (1964) $)^{14}$ and James (1967) ${ }^{19}$. The first study showed that when restraint was removed after closure of 
the interincisal diastema, the space was opened again. After a fresh diastema closure and frenectomy, when the restraint was removed, the space remained closed. James, on the other hand, selected 10 cases with a median diastema and complete and stable teeth in patients aged 12-22 years. One year after total frenectomy, diastema dimensions showed a decrease in eight patients, remained stable in one patient, and increased in the remaining patient.

In the presence of a diastema, frenectomy is indicated in the following situations:

- divergent or rotating central incisors;

- maxillary lateral incisor absent, the space between the central incisors must be closed before the fixed prosthesis;

- $\quad$ persistence of the diastema during retraction of the anterior block in Angle Class-II division 1;

- appearance of an interincisal diastema during orthodontic treatment (frequently associated with extraction of first premolars);

- absence of a central incisor whose therapeutic choice is to close space $^{19}$.

Even if the indications for frenectomy along with diastema closure are not common, it remains optional. However, controversy exists regarding the most appropriate time in the treatment plan to intervene. For some, frenectomy should precede diastema closure ${ }^{9}$, the downside being the risk of causing very fibrous scar tissue or granulation tissue that will be an obstacle to orthodontic closure. Thus, for others, the diastema must first be closed and the frenectomy performed during orthodontic restraint ${ }^{16,24}$, if possible at the end of skeletal growth. Some cases have even shown a spontaneous closure of the diastema after the frenum removal ${ }^{20}$

Delaire $(1974)^{10}$ recommends waiting until age 8 years to treat a maxillary frenum. This is because before that age, maxillary labial frenum, through its fibrous attachments at the interpremaxillary suture, represents a sutural disjunction factor and a growth factor under the influence of the traction of the upper labial muscles, and it is consequently an active expansion factor.

Depending on the criteria for bone growth, it would seem logical to intervene as late as possible. Indeed, the attachment height of a frenum depends in large part on the vertical development of alveolar processes ${ }^{34}$. A frenum may appear hyperplastic due to a lack of height of the alveolar structures ${ }^{15}$. It will therefore be necessary to take into account the patient's actual age, the eruption of the six anterior teeth, and also the alveolar bone development to determine the best time to intervene.

\section{OPERATIVE TECHNIQUES OF THE VESTIBULAR FRENECTOMY26}

Depending on the type of frenum attachment, a frenotomy or frenectomy may be performed. Frenotomy will be sufficient to treat a superficial frenum attachment. Frenectomy will treat a deep periosteal frenum attachment and may remove a frenum attached into the intermaxillary suture. 
Frenotomy leaves a periosteal wound whereas frenectomy exposes an area of decaying bone:

- $\quad$ up to the mucogingival line during the total frenectomy;

- only on the basis of the frenum in the partial frenectomy.

Submucosal parapical anesthesia is administered by a slow, traceable injection, at a distance from the periosteum, to avoid painful and traumatic distension of vestibular tissues. A palatal withdrawal may be considered if the frenum attachment is palatal.

The frenum is highlighted by a strong attachment to the lip (Fig. 7a) and immobilized by self-locking grips.

The incisions in the attached gingiva are beveled, $1 \mathrm{~mm}$ on either side of the frenum attachment on the gingiva, and delineate both sides of a triangle whose gingival apex may eventually be in the interdental space or on the palatal surface (Fig. 7b). If incisions extend into the interdental space, the marginal periodontium of each central incisor should be respected. Then a second triangle at the opposite apex is dissected

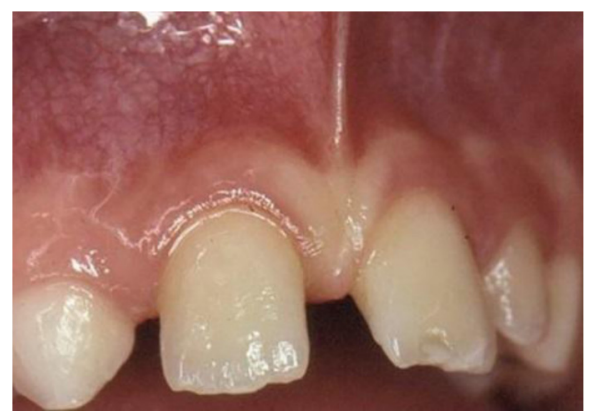

Figure $7 a$

The frenum is highlighted by a strong attachment to the lip. on the inner surface of the lip, in the labial mucosa, using a blade or gingiva scissors. The common base of the two triangles is the mucogingival line of the adjacent teeth.

All of the tissue within the diamond is resected. The frenum attachment is released in total thickness if the objective is a frenectomy, or in partial thickness if the objective is a frenotomy. The result is a diamond-shaped wound (Fig. 7c).

In the presence of a palate-attached frenum, it is advisable to remove the fibers located in the intermaxillary suture using a periodontal curette. Respect for the interdental papilla is strongly recommended especially in adults ${ }^{3}$.

The edges of the diamond are joined together by a series of discontinuous stitches or a single overstitch from the lip to the gingiva (Fig. 7d) using resorbable polyfilament (or nonabsorbable monofilamentous) suture thread 5/0 or $6 / 0$ in diameter on $1 / 2$ short circular needles (11-13 mm). The triangular excision area of the frenum in its gingival part is protected by a cross suture or a Surgicel ${ }^{\circledR}$ type cellulose pad.

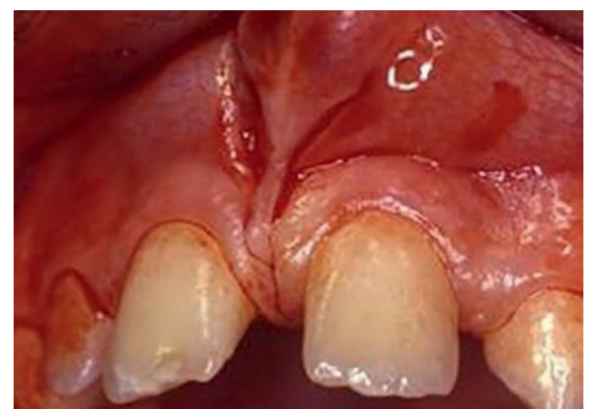

Figure $7 b$

The incisions in the attached gingiva are beveled, at $1 \mathrm{~mm}$ on both sides of the frenum attachment on the gingiva of the interdental papilla. 


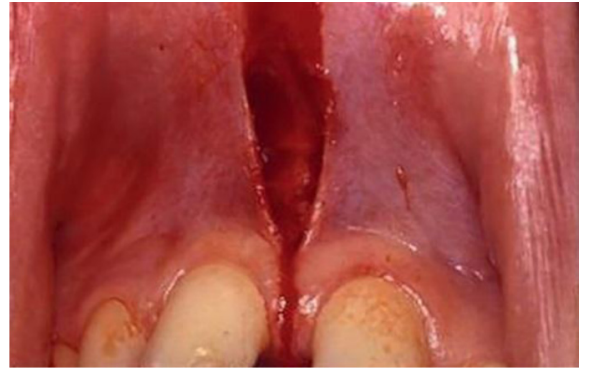

Figure $7 c$

The incisions in the attached beveled gumline delineate the two sides of a triangle.

The second triangle at opposite vertex is dissected on the inner side of the lip, in the labial mucosa. The common base of the two triangles corresponds to the mucogingival line. The entire area is in the shape of a diamond.

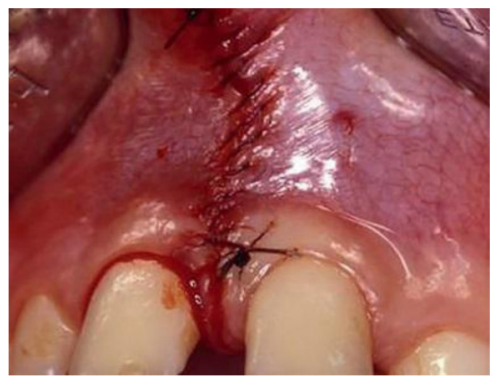

Figure $7 d$

The edges of the diamond are brought together by a series of interrupted sutures or a simple overlocking stich starting from the lip toward the gingiva.

The sutures can be removed, starting on the 7th postoperative day in children and adolescents, who heal very quickly (Fig. 7th), whereas on the 10th day in adults.

The postoperative results of this cold blade technique are very rarely painful according to our clinical experience. However, we can find in the scientific literature a case for using $\mathrm{CO}_{2}$ laser to replace the blade and with the goal of decreasing postoperative pain ${ }^{2}$.

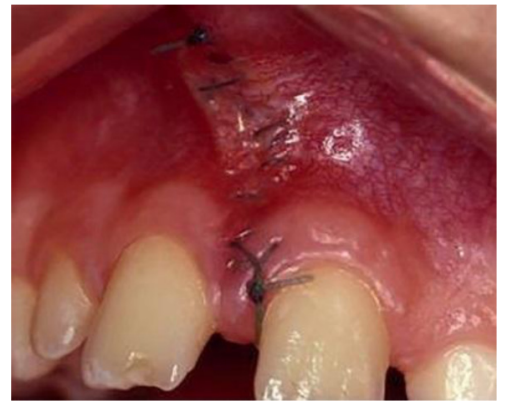

Figure $7 e$

Sutures are removed in adolescents who heal very quickly, starting on the 7th postoperative day.

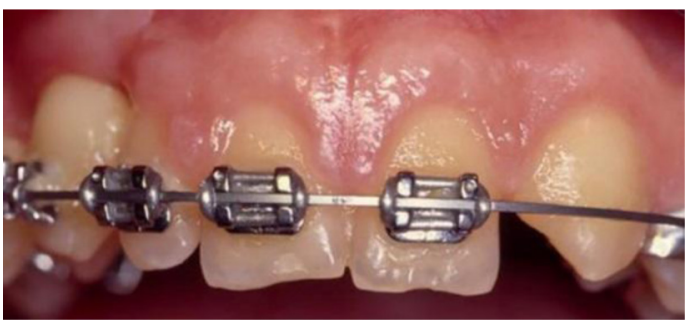

Figure $7 f$

Closing of the diastema. The interincisal interdental papilla has a harmonious architecture.

If the frenum is oversized and has a papillary attachment, and the area left bare very wide, or if the site is involved in the esthetics of the smile, a triangular gingival graft transplant from an adjacent vestibular interdental donor site may be added 5 . The advantage is that it prevents second-line healing, which can result in a different color and/or texture of the gingiva. A laterally positioned flap ${ }^{24}$ can also play this protective role. Bagga $(2006)^{3}$ describes the possibility of making a flap displaced laterally bilaterally. At the mandible, the technique utilized relies upon the amount and thickness of keratinized and attached tissue and/or the presence of a recession on the mandibular 


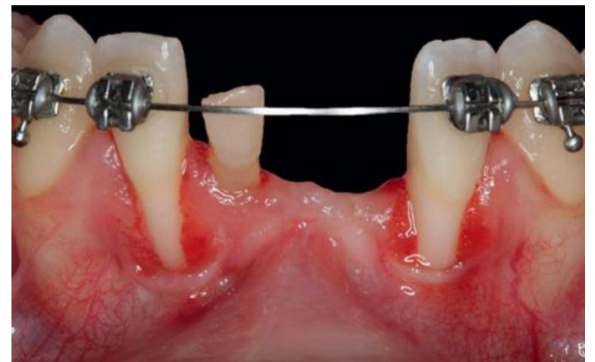

Figure $8 a$

17-year-old patient with agenesis of 31/41 with persistence of 81, Miller class-III recessions on 32/42 and a hypertrophic lower labial frenum that fits high on the bony crest.

incisors. Frequently, a frenectomy can be performed alone to precede a buried mucosal graft transplant or at the same time as an epithelial-mucosal graft transplant, which has the advantage of simultaneously strengthening the

\section{RESULTS}

Results are good if two fundamental principles are respected:

- partial or complete dissection of the frenum attachment;

- immobilization of the labial or lingual alveolar mucosa at a distance from the attached gingiva or healing site by second intention.

\section{Elimination of traction on the free gingiva}

The frenectomy is effective in restoring anatomical conditions conducive to

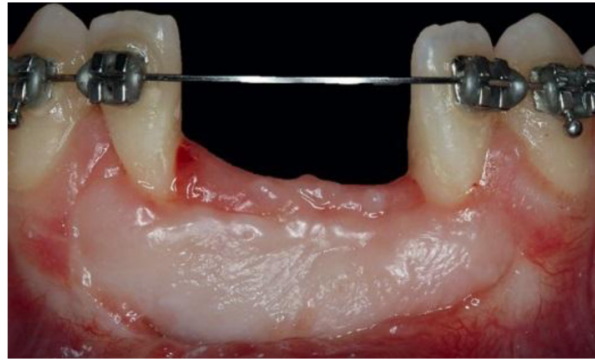

Figure $8 b$

Situation 2 months after frenectomy and free gingiva graft. The mucogingival complex was reinforced at the 32/42 level and at the ridge level and the vestibule was deepened.

mucogingival complex and deepening the vestibule (Fig. 8a and b)

The maxillary and mandibular lateral frena are most often repositioned by frenotomy because they are smaller than the median frenum, but the indications for frenectomy remain the same.

the long-term maintenance of periodontal health (Fig. $7 f$ and Fig. 9a and b).

\section{Restoration of esthetic gingival contour}

For the esthetics of the gingival smile, it is an effective cosmetic procedure if care is taken not to allow the development of unsightly scars from the surgical technique to develop. Sometimes frenectomy healing without tissue input can leave a thin scar that fades over time, while combining the frenectomy with a triangular gingival graft taken from the vestibule, the esthetic result is optimal. 


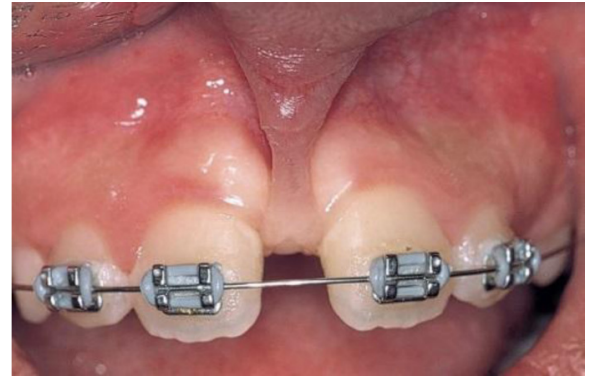

Figure 9a

Palatal frenum attachment pulling on the marginal gingiva of 11 and 21.

\section{Optimal Healing of Periodontal Surgery}

Frenectomy is an essential prerequisite for performing surgical techniques that move tissues and/or require perfect immobilization during healing (in all periodontal regeneration techniques). The frenectomy assists the technical achievement and immediate postoperative tissue stability (Fig. 5b).

\section{Stable closure of the diastema (Fig. 10a and b)}

Edwards (1977) ${ }^{13}$ showed that in the presence of abnormal frenum associated with diastema, there is a strong tendency for recurrence after orthodontic closure.

For Naves (1967) 28 , frenectomy has, in some cases, a therapeutic role on the diastema. In fact, diastemas were completely decreased after a few weeks by this single intervention. But what about the participation of growth and eruption, even for only a few weeks, if these are very active periods?

In any case, to avoid diastema recurrence, it would appear to be more important to have a gingival band attached

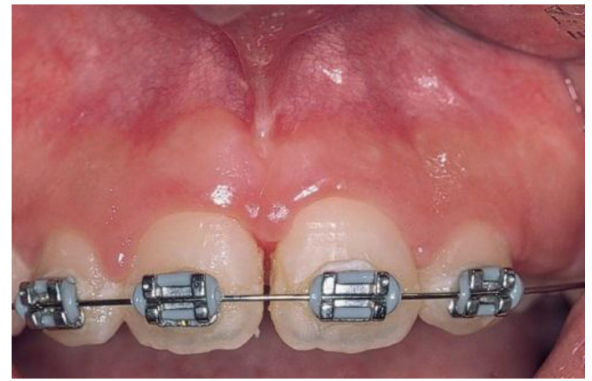

Figure $9 b$

Healing 3 months after the frenectomy and closure of the diastema.

along the median line and that the central incisors be all at once (crown and root) ${ }^{24}$.

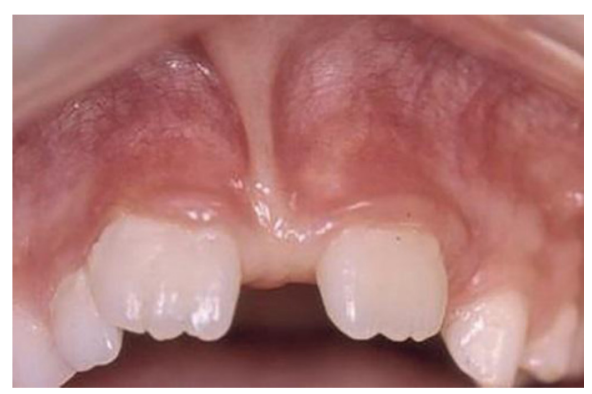

Figure 10a

Very large frenum associated with a very wide diastema preventing the eruption of the lateral incisors: absence of the eruption corridor.

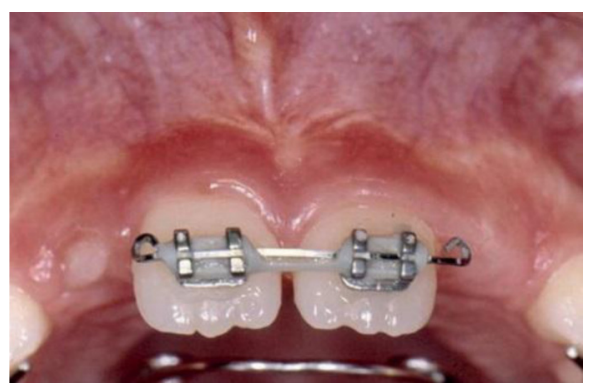

Figure $10 b$

Very fast closure of the diastema and spontaneous eruption of 12 and 22 a few weeks after the frenectomy. 


\section{CONCLUSION}

The frenectomy is a simple and routine procedure in periodontal plastic surgery, which should be performed at the right time, according to the indications. In some more complex cases, a free or pedicle epithelial-mucosal graft transplant may be required along with frenectomy.

Conflict of interest: The authors declare no conflicts of interest.

\section{REFERENCES}

1. Addy M, Dummer PMH, Hunter ML, Kingdon A, Shaw WC. A study of the association of frenal attachment, lip coverage and vestibular depth with plaque and gingivitis. J Periodontol 1987;58:752757.

2. Akpınar A, Toker $H$, Lektemur Alpan A, Çalıs, ır M. Postoperative discomfort after Nd:YAG laser and conventional frenectomy: comparison of both genders. Australian Dental Journal 2016;61(1):71-75.

3. Bagga $\mathrm{S}$, Bhat KM, Bhat GS, Thomas BS. Esthetic management of the upper labial frenum: a novel frenec- tomy technique. Quintessence Int 2006;37:819-823.

4. Benoit R. Orthodontie et structures muco-gingivales chez l'enfant et l'adolescent. Rev Orthop Dent Fac 1982;16:7-36.

5. Borghetti A, Guy JP, Cesano B. La frénectomie associée à une greffe gingivale triangulaire. J Parodontol 1991;10:373-378.

6. Bork KC, Weiler JE. Frenum reduction as a treatment for periodontal atrophy. Oral Surg Oral Med Oral Pathol 1958:11:370-376.

7. Bouchard P, Fournier B, Godeau G, Gogly B, Senni K. La gencive in Bouchard P. Traité de Parodontologie et de dentisterie implantaire. Vol. 1. Médecine parodontale. Lavoisier Médecine Sciences éd. Paris, 2015:9-20.

8. Boutsi E, Tatakis D. The maxillary labial frenum attachment in children. Int J Paediatr Dent 2011;21: 284-288.

9. Campbell PM, Moore JW, Mattews JL. Orthodontically corrected midline diastemas. Am J Orthod 1975;67:139- 158.

10. Delaire J. Considérations sur l'accroissement du pré-maxillaire chez l'homme. Rev Stomatol 1974;75:951-970.

11. Durand BM. Chirurgie muco-gingivale. Encycl Med Chir (Paris, Éditions techniques) 1994;23-445-K-10.

12. Edwards JG. Soft-tissue surgery to alleviate orthodontic relapse. Dent Clin North Am 1993;37: 205-225.

13. Edwards JG. The diastema, the frenum, the frenectomy. A clinical study. Am J Orthod 1977;71:489508.

14. Ewen SJ, Pasternak R. Periodontal surgery. An adjunct to orthodontic therapy. Periodontics 1964;2:162-165.

15. Forester J. Pediatric dental medicine. Philadelphie: Lea and Febiger, 1981:198-201.

16. Genon P, Koskas HS. La chirurgie muco-gingivale. II. Les techniques opératoires. J Parodontol 1985;4: 145-165. 
17. Gottsengen R. Frenum position and vestibule depth in relation to gingival health. Oral Surg Oral Med Oral Pathol 1954;7:1069-1078.

18. Hall WB. Pure mucogingival problems. Etiology, treatment, and prevention. Chicago: Quintessence Publishing Co, 1984:75-93.

19. James GA. Clinical implications of a follow-up study after frenectomy. Dent Pract 1967;17:299-305.

20. Koora K, Muthu MS, Rathna PV. Spontaneous closure of midline diastema following frenectomy. J Indian Soc Pedod Prev Dent 2007;25:23-26.

21. Lang NP, Löe $H$. The relationship between the width of keratinized gingiva health. J Periodontol 1972;43:623- 627.

22. Liébart MF, Fouque-Deruelle C, Santini A, Dillier FL, Monnet-Corti V, Glise JM et al. Smile line and periodontium visibility. Periodont Pract Today 2004;1:17-25.

23. Maynard JG, Wilson RD. Diagnosis and management of mucogingival problems in children. Dent Clin North Am 1980;24:683-703.

24. Miller PD Jr. The frenectomy combined with a laterally positionned pedicle graft. Functional and esthetic considerations. J Periodontol 1985;56:102-106.

25. Miller PD, Allen EP. The development of periodontal plastic surgery. Periodontol 2000 1996;11:7-17.

26. Monnet-Corti V, Moll V, Borghetti A. Frénectomie in Borghetti A, Monnet-Corti V. Chirurgie plastique paro- dontale. 3e éd. Éditions CdP. Collection JPIO. Rueil- Malmaison, 2017:199-212.

27. Nanda R, Torres Diaz MA. Orthodontic space closure.Dent Clin North Am 1981;25:95-107.

28. Naves R. Contribution à l'étude des diastèmes interincisifs. Orthodont Fr 1967;38:395-398.

29. Nevins M, BeckerW, Kornman K. Proceedings of the World Workshop in Clinical Periodontics. Princeton: American Academy of Periodontology 1989:7-8.

30. Peacock ME. Frenectomy and keratinized tissue augmentation. Gen Dent 1998;46:194-196.

31. Pini Prato GP, Clauser C, Cortellini P. Periodontal plastic and mucogingival surgery. Periodontol 2000 1995:9:90-105.

32. Placek M, Skach M, Mrklas L. Significance of the labial frenum attachment in periodontal disease in man. Part I. Classification and epidemiology of the labial frenum attachment. J Periodontol 1974;45:891-894.

33. Popovich F, Thompson GW, Main PA. The maxillary inter-incisal diastema and its relationship to the superior labial frenum and intermaxillary suture. Angle Orthod 1977:4:265-271.

34. Popovich F, Thompson GW. Maxillary diastema: indications for treatment. Am J Orthod 1979;75: 399-404.

35. Powell RN, McEniery TM. A longitudinal study of isolated gingival recession in the mandibular central incisor region of children aged 6-8 years. J Clin Periodontol 1982;5:357-364.

36. Ramfjord SP. Periodontology and periodontics. Theoretical and practical. Paris: Masson, 1993.

37. Vanarsdall RL. Orthodontic periodontal considerations for minor periodontal surgery. In: Schatz J, Joho J (eds). Chicago: Quintessence Publishing Co, 1992:91-105.

38. Whinston GJ. The frenectomy and mucobuccal fold resection utilized in periodontal therapy. NY State Dent J 1956;22:495-499. 